\title{
Factors Associated with Overweight and Obesity among Reproductive Age Women of Kaski District, Nepal
}

\author{
Narayan Tripathi, ${ }^{1}$ Arun Kumar Koirala, ${ }^{1}$ Rojana Dhakal ${ }^{1}$ \\ ${ }^{1}$ School of Health and Allied Sciences, Faculty of Health Sciences, Pokhara University, Nepal
}

\begin{abstract}
Introduction: Overweight and obesity are associated with numerous comorbidities so they are of great public health concern. In Nepal, the proportion of overweight and obese women of reproductive age has been gradually increasing which marks obesity as a serious public health challenge. The study aimed to assess the factors associated with overweight and obesity among reproductive aged women residing in Pokhara metropolitan.
\end{abstract}

Methods: A cross-sectional study was conducted among 278 married women of reproductive age at Pokhara metropolitan, Kaski district, Nepal using probability proportional to size sampling method. Face to face interview was conducted among respondents through pretested questionnaire. Similarly, height and weight were also measured. Based on anthropometric measurements, Body Mass Index was computed and defined according to the World Health Organization criteria. The association between overweight /obesity and the explanatory variables were assessed in bivariate analysis using the Chi-square test and the association was further explored by using multivariate logistic regression.

Results: The prevalence of overweight and obesity was $49.6 \%$; with $33.7 \%$ of overweight and $15.9 \%$ of obesity. Factors associated with overweight/obesity were age $(\mathrm{AOR}=13.85,95 \% \mathrm{CI}: 5.77-40.80)$, business as occupation $(\mathrm{AOR}=7.39$, 95\%CI: 2.25-14.17), fast food consumption of three or more times a week (AOR=3.42, 95\%CI: 1.01-11.63), energy intake above the RDA (AOR=5.45; 95\%CI: 2.19-13.55), low or moderate physical activity level (AOR=2.84; 95\%CI: 1.18-6.83) and multiparity ( $\mathrm{AOR}=17.80 ; 95 \% \mathrm{CI}: 4.04-89.06)$.

Conclusion: The study provides evidence that the prevalence of overweight, obesity is remarkably high in married women of reproductive age in Pokhara metropolitan. The study concluded older age, business as occupation, consumption of fast foods for three or more times per week, low or moderate physical activity level, energy intake above the RDA and multiparty had higher odds of being overweight/obesity. On the other hand fruits and vegetables consumption were found to be protective against overweight/obesity.

Keywords: Overweight, Obesity, Reproductive age, Women, Prevalence

\section{INTRODUCTION}

Obesity is increasing at an alarming rate throughout the world and has now become a global epidemic. ${ }^{1}$ The World Health Organization (WHO) has declared overweight as one of the top 10 health risks in the world and one of the top five in developed nations. ${ }^{2}$ Once associated with high-income countries; obesity is now also prevalent in low and middle-income countries. Most of the developing countries at present experience a dual burden of disease with over nutrition and under nutrition occurring simultaneously ${ }^{3,4}$ including Nepal., ${ }^{5,6}$

Overweight and obesity are associated with numerous co-morbidities. It is of great public health concern, particularly cardiovascular diseases, type 2 diabetes, high blood pressure, high blood cholesterol, high triglycerides, certain types of cancer, and sleep apnea. ${ }^{7,8}$ There are many obesity-related conditions, which uniquely or mostly affect women. These include: osteoarthritis, birth defects, breast and endometrial cancers, cardiovascular and gall bladder diseases, infertility and gynecological complications and stigma/discrimination. ${ }^{9}$ In addition, the compromised quality of life resulting from overweight and obesity is related to higher medical, psychological, and social burden to the society. ${ }^{7}$

Globally, each year at least 2.8 million people die as a result of being overweight or obese. Obesity has nearly tripled since 1975. In 2016, more than 1.9 billion adults, 18 years and older, were overweight; of these, over 650 million were obese. $39 \%$ of adults aged 18 years and over were of overweight in 2016, and $13 \%$ were obese. ${ }^{1}$

Correspondence: Narayan Tripathi, School of Health and Allied Sciences, Faculty of Health Sciences, Pokhara University, Nepal, E-mail: ng.babu28@gmail.com 
According to Nepal National Micro-nutrient Status Survey Report -2016, among women of 15-49 year the prevalence of overweight is $18.5 \%$ and obesity is $4.6 \% .^{10}$ Overweight and obesity among adults is increasing ${ }^{11-13}$ and according to Nepal Demographic Health Survey 2016, the prevalence of overweight is higher in females (22\%) when it is compared with men $(17 \%) \cdot{ }^{13}$ Between 2006 to 2016, the proportion of women who were overweight or obese increased from $9 \%$ to $22 \% .{ }^{13}$ Different studies show that the prevalence is much higher in urban areas compared to the national level and rural areas. ${ }^{13-16}$ Similarly, among non-pregnant women of 15-49 years the prevalence of overweight is $18.5 \%$ and obesity is $4.6 \% .^{10}$ Prevalence of overweight and obesity is high in the age group of 30-44 years (24.6\% overweight and $4.6 \%$ of obesity) with overall overweight and obesity being $18 \%$ and 3.1\% among women of $15-69$ years. ${ }^{12}$ So this study aimed to assess the factors associated with overweight and obesity among reproductive aged women residing in Pokhara metropolitan.

\section{METHODS}

A cross-sectional analytical study was conducted among 278 married women of reproductive age (15-49 years) at Pokhara metropolitan, Kaski district, Nepal. Probability proportional to size sampling was used as the sampling strategy for the study. For the sample size calculation, Nepal Demographic and Health Survey 2016 prevalence of overweight and obesity among women was taken as reference which is $22 \%$. Permitted error of $5 \%$ was taken $(\mathrm{CI}=95 \%), \mathrm{q}=1-\mathrm{p}(1-0.22=0.78)$. Therefore, $\mathrm{n}=\mathrm{Z}^{2} \mathrm{pq} / \mathrm{d}^{2}=1.96 * 1.96 * 0.22 * 0.78 / 0.05^{2}=264$. The non response rate of $5 \%$ was kept thus the sample size was 278 . The data was collected after obtaining informed consent from respondents. Face to face interview was conducted among respondents through pretested questionnaire. Similarly, height and weight were also measured. Based on anthropometric measurements, Body Mass Index was computed and it was defined according to the WHO criteria.

Validity of the instruments was maintained by incorporating expert's opinion and through extensive literature review. Content validity of the tool was established using a panel of three judges, competent in the field of nutrition, who were requested to assess the relevance of the content used in the questionnaire. Tool to determine physical activity level (IPAQ-L) was adopted which have international acceptability and validity. The anthropometric measurement tools were validated from Nepal Bureau of Standards \& Metrology (NBSM), (Pokhara branch) which is the National Standards Body of Nepal. A standard weight of $1 \mathrm{~kg}$ validated from NBSM was taken and it was used to calibrate the digital weighing scale at interval of five participant's weight measurement.
Data were entered in Epi data software except for dietary intake and analyzed by using SPSS 20 version software. The association between overweight /obesity and the explanatory variables were assessed in bivariate analysis using the Chisquare test and the association was further explored by using multivariate logistic regression. Ethical approval was taken from Institutional Review Committee of Pokhara University Research Centre. Similarly, administrative approval was also taken from Pokhara metropolitan Health Division.

\section{RESULTS}

Table 1:Socio-demographic characteristics of the respondents

\begin{tabular}{|c|c|c|}
\hline Variable & $\begin{array}{c}\text { Frequency } \\
(\mathrm{n}=276)\end{array}$ & Percentage \\
\hline \multicolumn{3}{|l|}{ Age category } \\
\hline$<30$ years & 90 & 32.6 \\
\hline 30-39 years & 124 & 44.9 \\
\hline $40-49$ years & 62 & 22.5 \\
\hline \multicolumn{3}{|c|}{ Mean \pm SD : $33.1 \pm 8.14$, Min: 18, Max: 49} \\
\hline \multicolumn{3}{|l|}{ Family type } \\
\hline Nuclear & 190 & 68.8 \\
\hline Joint/Extended & 86 & 31.2 \\
\hline \multicolumn{3}{|l|}{ Family size } \\
\hline$\leq 4$ members & 154 & 55.8 \\
\hline$>4$ members & 122 & 44.2 \\
\hline \multicolumn{3}{|l|}{ Mean \pm SD: 4.8 Min:2, Max: 12} \\
\hline \multicolumn{3}{|l|}{ Ethnicity } \\
\hline Upper Caste & 159 & 57.6 \\
\hline Advantages Janajatii & 62 & 22.5 \\
\hline Disadvantages Janajati & 39 & 14.1 \\
\hline Dalit & 13 & 4.7 \\
\hline Others & 3 & 1.1 \\
\hline \multicolumn{3}{|l|}{ Level of Education } \\
\hline Illiterate & 8 & 2.9 \\
\hline Literate with no formal school & 15 & 5.4 \\
\hline Primary & 70 & 25.4 \\
\hline Secondary Level & 114 & 41.3 \\
\hline Bachelors and above & 69 & 25.0 \\
\hline \multicolumn{3}{|l|}{ Occupation } \\
\hline House maker & 135 & 48.9 \\
\hline Students & 35 & 12.7 \\
\hline Business & 62 & 22.5 \\
\hline Service Sector & 24 & 8.7 \\
\hline Agriculture & 12 & 4.3 \\
\hline Daily wages & 8 & 2.9 \\
\hline
\end{tabular}

Table 1 shows that the mean age of the respondents was $33.1 \pm 8.1$ years, ranging from 18 to 49 years and almost half $(44.9 \%)$ of the respondents were between the age of 30 to 39 years. More than two third (68.7\%) of the respondents were from 
nuclear family and more than half (55.8\%) of the respondents had four or less members in their family. More than half (57.6\%) of the respondents were from the upper caste ethnic group. Similarly, more than two fifth (41.3\%) of women had educational attainment of secondary level (SLC or +2 level). About two fifth $(38.0 \%)$ of women had business as the major source of income in the family and about half of the women (48.9\%) were house makers by occupation.

Table 2: Prevalence of overweight and obesity according to BMI classification

\begin{tabular}{lcc}
\hline BMI Classification & Frequency & Percentage \\
\hline Normal/underweight $(\mathrm{BMI}<25)$ & 139 & 50.4 \\
Overweight/Obese $(\mathrm{BMI} \geq 25)$ & 137 & 49.6 \\
Mean \pm SD: $25.67 \pm 4.51$ Min $:$ & 16.94, Max: 42.86 & \\
\hline
\end{tabular}

Table 2 shows that about half $(49.6 \%)$ of the respondents were overweight/obese. The mean BMI was $25.67 \pm 4.51$ ranging from 16.92 to 42.86 .

Table 3: Physical activity, dietary practices and reproductive factors of reproductive age women

\begin{tabular}{lcc}
\hline Variables & Frequency & Percentage \\
\hline Physical activity & 9 & 3.3 \\
Low & 119 & 43.1 \\
Moderate & 150 & 53.6 \\
High & & \\
Median MET, $\left(\mathrm{Q}_{1} \sim \mathrm{Q}_{3}\right):$ 3213, (2319.63 $\left.~ 3213\right)$ & \\
Dietary practice & & \\
Main diet & 273 & 98.9 \\
Rice/dal/vegetable & 3 & 1.1 \\
Wheat Roti & 166 & 60.1 \\
Vegetables or fruits servings consumption / week & 39.9 \\
$\leq 21$ servings & 110 & \\
$>21$ servings & & 27.5 \\
Eating away from home & 76 & 35.5 \\
Occasional & 98 & 37.0 \\
Once or twice a week & 102 & \\
Three or more times a week &
\end{tabular}

Frequency of consumption of fast food/processed food

$\begin{array}{lcc}\text { Occasional } & 85 & 30.8 \\ \text { Once or twice a week } & 132 & 47.8 \\ \text { Three or more times a week } & 59 & 21.4 \\ \text { Energy intake/day(RDA=2230 kcal/day ) } & & \\ \text { SRDA } & 171 & 62.0 \\ >\text { RDA } & 105 & 38.0\end{array}$

Mean \pm SD: $2236.8 \pm 281.4$,Min: 1325 Max: 2961

Reproductive factors

Age at menarche

$\begin{array}{lll}<14 \text { years } & 165 & 59.8 \\ \geq 14 \text { years } & 111 & 40.2\end{array}$

Mean \pm SD: $13.58 \pm 1.4$; Min: 11 , Max:19

Parity

$\begin{array}{lll}\text { Nulliparity } & 46 & 16.7\end{array}$

1 parity $\quad 71 \quad 25.7$

$\geq 2$ parity $\quad 159 \quad 57.6$

Ever used any contraceptive devices

$\begin{array}{lll}\text { Yes } & 131 & 47.5\end{array}$

No $\quad 145 \quad 52.5$

Using contraceptive device currently $(\mathrm{n}=131)$

$\begin{array}{lll}\text { Yes } & 56 & 42.7\end{array}$

$\begin{array}{lll}\text { No } & 75 & 57.3\end{array}$

Table 3 shows that more than half $(53.6 \%)$ of the respondents were highly physically active (MET $\geq 3000$ ) with median MET of 3212 per week. Under the dietary practices adopted by the respondents, rice was the main diet of the majority $(98.9 \%)$ respondents. Similarly, three fifth of the respondent $(60.1 \%)$ consumed less than 21 servings of fruits or vegetables per week. About two fifth of respondent $(37.0 \%)$ eat three or more time away from home per week. About half of the respondents $(47.8 \%)$ consumed fast or processed food once or twice a week. The mean age at menarche was 13.58 years, ranging from 11 to 19 years, and about three fifth $(59.8 \%)$ of respondents menarche age was below 14 years. Of the respondents $16.7 \%$, were nulliparous. More than half (52.5\%) of the respondents had ever used contraceptive devices and of them, more than two fifth $(42.7 \%)$ were currently using contraceptive devices.

Table 4: Association of socio-demographic and socio economic factors with overweight including obesity

\begin{tabular}{|c|c|c|c|c|c|c|}
\hline \multirow{2}{*}{ Variables } & \multicolumn{2}{|c|}{ Overweight/ Obesity (BMI $\geq 25)$} & \multirow{2}{*}{$\chi^{2}$ statistics } & \multirow{2}{*}{$\mathrm{p}$ value } & \multirow{2}{*}{ UOR (At 95\% CI) } & \multirow{2}{*}{ AOR (At 95\% CI) } \\
\hline & Yes & No & & & & \\
\hline \multicolumn{7}{|l|}{ Age group } \\
\hline 30-39 years & $69(50.4)$ & $55(39.6)$ & & & $3.151(4.098-5.992)$ & $13.855(5.779-50.801)^{* *}$ \\
\hline $40-49$ years & $50(36.5)$ & $12(8.6)$ & & & $4.098(1.741-9.647)$ & $18.794(4.015-82.969)^{* *}$ \\
\hline Primary or below & $60(43.8)$ & $33(23.7)$ & 20.014 & $<0.001^{* *}$ & Ref & Ref \\
\hline Secondary level & $57(41.6)$ & $57(41.0)$ & & & $0.550(0.314-0.964)$ & $1.504(0.560-4.036)$ \\
\hline Bachelors and above & $20(14.6)$ & $49(35.3)$ & & & $0.224(0.115-0.439)$ & $0.922(0.247-3.446)$ \\
\hline
\end{tabular}




\begin{tabular}{|c|c|c|c|c|c|c|}
\hline \multicolumn{7}{|l|}{ Occupation } \\
\hline Notemployed outside home & $72(52.6)$ & $98(70.5)$ & 14.720 & $0.002^{*}$ & Ref & Ref \\
\hline Business & $43(31.4)$ & $19(13.7)$ & & & $3.080(1.658-5.725)$ & $7.390(2.259-14.174)^{* *}$ \\
\hline Others & $12(8.8)$ & $8(5.8)$ & & & $2.042(0.794-5.252)$ & $1.297(0.255-6.586)$ \\
\hline
\end{tabular}

Table 4 shows that variables with $\mathrm{p}<0.05$ i.e. age and occupation were significantly associated with overweight including obesity. With reference to women age less than 30 years (18-30 years), the odds were 13.85 times raised among the women of age $30-39$ years ( $\mathrm{AOR}=13.855,95 \% \mathrm{CI}: 5.779-40.801)$ and 18.79 times raised among women of age 40-49 years. (AOR=18.794, 95\%CI: 4.015 72.969). Similarly, compared to women who do not work outside the home (House maker and students), women having business as an occupation were 7.39 times more likely to be overweight including obesity ( $\mathrm{AOR}=7.390,95 \% \mathrm{CI}$ : 2.259-14.174).

Table 5: Association of behavioral factors with overweight including obesity

\begin{tabular}{|c|c|c|c|c|c|c|}
\hline \multirow{2}{*}{ Variables } & \multicolumn{2}{|c|}{$\begin{array}{l}\text { Overweight/ Obesity } \\
\quad(\mathrm{BMI} \geq 25)\end{array}$} & \multirow{2}{*}{$\begin{array}{c}\chi^{2} \\
\text { statistics }\end{array}$} & \multirow{2}{*}{$\begin{array}{c}\mathrm{p} \\
\text { value }\end{array}$} & \multirow{2}{*}{ UOR (At 95\% CI) } & \multirow{2}{*}{ AOR (At 95\% CI) } \\
\hline & Yes & No & & & & \\
\hline \multicolumn{7}{|c|}{ Vegetables or fruits consumption per week } \\
\hline$\leq 21$ servings & $113(82.5)$ & $53(38.1)$ & 56.621 & $<0.001^{*}$ & Ref & Ref \\
\hline$\geq 22$ servings & $24(17.5)$ & $86(61.9)$ & & & $0.131(0.075-0.229)$ & $0.141(0.056-0.354)^{* *}$ \\
\hline \multicolumn{7}{|c|}{ Frequency of fast food of consumption } \\
\hline Occasional & $36(26.3)$ & $49(35.3)$ & 10.206 & $0.006^{*}$ & Ref & Ref \\
\hline Once or twice a week & $61(44.5)$ & $71(51.1)$ & & & $1.169(0.675-2.026)$ & $1.563(0.595-4.108)$ \\
\hline Three or more times a week & $40(29.2)$ & $19(13.7)$ & & & $2.865(1.430-5.743)$ & $3.427(1.009-11.632)^{* *}$ \\
\hline \multicolumn{7}{|c|}{ Energy intake $/$ day $(\mathrm{RDA}=2230 \mathrm{kcal} /$ day $)$} \\
\hline$\leq \mathrm{RDA}$ & $67(48.9)$ & $104(74.8)$ & 19.659 & $<0.001^{*}$ & Ref & Ref \\
\hline$>$ RDA & $70(51.1)$ & $35(25.2)$ & & & $3.104(1.866-5.164)$ & $5.452(2.194-13.550)^{* *}$ \\
\hline \multicolumn{7}{|l|}{ Level of Physical activity } \\
\hline Low and Moderate & $76(55.5)$ & $52(37.4)$ & 9.054 & $0.003^{*}$ & $2.085(1.288-3.373)$ & $2.844(1.183-6.837) * *$ \\
\hline High & $61(44.5)$ & $87(62.6)$ & & & Ref & Ref \\
\hline
\end{tabular}

Table 5 shows that as compared to women consuming 21 servings or less fruits or vegetables per week , those consuming more than 21 servings were less likely to be overweight/obese with $85.9 \%$ lower odds of being overweight/obesity ( $\mathrm{AOR}=0.141$; 95\%CI: 0.056-0.354). Meanwhile, women consuming fast food for three or more times a week were 3.4 times more likely (AOR=3.427, 95\%CI: 1.009-11.632) to be overweight/obese than those consuming fast occasionally (less than one time a week). Likewise, women who had more energy intake than RDA were 5.45 times $(\mathrm{AOR}=5.452 ; 95 \% \mathrm{CI}: 2.194-13.550)$ more likely to be overweight, including obesity compared to women who had intake energy less than or equal to RDA.

Regarding physical activity level of women this study revealed, those women who had low or moderate level of physical were 2.84 times $(\mathrm{AOR}=2.844$; 95\%CI: 1.183-6.837) more likely to be overweight including obesity as compared to women who were highly physically active. 
Table 6: Association of reproductive factors with overweight including obesity

\begin{tabular}{|c|c|c|c|c|c|c|}
\hline Variables & \multicolumn{2}{|c|}{ Overweight/ Obesity (BMI $\geq 25$ ) } & $\chi^{2}$ statistics & $\mathrm{p}$ value & UOR (At 95\% CI) & AOR (At 95\%CI) \\
\hline \multicolumn{7}{|l|}{ Parity } \\
\hline 1 parity & $27(19.7)$ & $44(31.7)$ & & & $3.419(1.340-8.721)$ & $4.646(1.279-45.304)$ \\
\hline$\geq 2$ Parity & $103(75.2)$ & $56(40.3)$ & & & $10.247(4.302-24.407)$ & $17.803(4.046-89.067)^{* *}$ \\
\hline Yes & $87(63.5)$ & $44(31.7)$ & 28.067 & $<0.001^{*}$ & $3.757(2.282-6.186)$ & $1.959(0.732-5.244)$ \\
\hline No & $50(36.5)$ & $95(68.5)$ & & & Ref & Ref \\
\hline \multicolumn{7}{|c|}{ Using any device contraceptive currently } \\
\hline Using & $35(25.5)$ & $21(15.1)$ & 4.649 & $0.031^{*}$ & $1.928(1.056-3.522)$ & $2.509(0.732-8.599)$ \\
\hline Not Using & $102(47.5)$ & $118(84.9)$ & & & Ref & Ref \\
\hline
\end{tabular}

Of the three reproductive variable which were significant in the chi-square, only parity remained statistically significant $(p<0.05)$ whereas, variables ever use of contraceptive devices and using any contraceptive devices currently do not remained statistically significant in multivariate analysis.

\section{DISCUSSION}

The present study was undertaken to assess the prevalence of overweight and obesity and their determinants among married women of reproductive age at Pokhara metropolitan, where socio-demographic, behavioral and reproductive factors were assessed.

This study reported the prevalence of overweight/obesity to be $49.6 \%$ (overweight $33.7 \%$ and obesity $15.9 \%$ ) with the mean BMI of $25.67 \pm 4.5$. Studies from Nepal like step survey of 2003 conducted in Kathmandu reported $41.86 \%$ to be overweight/ obesity with mean BMI 24.56 (overweight 31.22, obesity $10 \%)$. Similarly, studies from Kathmandu and Dharan reported $47.4 \%$ and $48 \%$ of reproductive age women to be overweight/ obese respectively. ${ }^{17,18}$ Likewise, study among adults from India uttarakhand ${ }^{19}$ and another study of Delhi reported $55.5 \%$ and $50.1 \%$ to be overweight including obesity respectively. ${ }^{20}$ In contrast, this study reported higher prevalence of overweight and obesity among 15-49 years than the prevalence from the national level surveys NDHS 2016 and NNMSS 2016, which reported $22 \%$ of overweight/obese respectively among 15-49 non pregnant women. While NCD Step Survey 2016 reported $22.1 \%$ (overweight $17.3 \%$ and obesity $4.8 \%$ ) of $15-69$ years non pregnant women were overweight /obese. Similarly, this study also over reported the higher prevalence of overweight/obesity than the study conducted at Ramkot VDC of Kathmandu where the prevalence was $26.3 \%$ (overweight $24.5 \%$ and obesity $1.8 \%)^{16}$ and a study among ever-married women in India where the prevalence was $34.6 \%$ in Delhi and $36.0 \%$ in Punjab. ${ }^{21}$ This indicates that there is a difference in prevalence of overweight and obesity in rural and urban region with urban region having a higher prevalence than in rural area.

Age was found significantly associated with overweight, including obesity from studies in Nepal ${ }^{22,18}$ and other different parts of the world..$^{23}$ The results of this study were also consistent with studies in India and Ghana, where in India women age 40-49 years were 12.35 times and age 30-39 years were 8.48 times more likely to be obese ${ }^{21}$ and in Ghana women within the age $35-44$ years had the highest odds $(3.55, \mathrm{p}=0.000)$ of being overweight or obese. ${ }^{24}$

The findings of this study showed that occupation was significantly associated with overweight, including obesity, which is similar to the finding from Benin $(\mathrm{p}<0.05)^{26}$ and from India. ${ }^{25}$ The findings of this study showed women having selfrun business as occupation (Odds: 7.39) exhibited significantly greater odds for being overweight, including obesity $(\mathrm{p}=0.001)$ in compared to housewife, this could be compared to the study findings of Bangladesh where women having job that required mostly sitting were more likely to be overweight/obesity in compare with jobs that required manual labor $(\mathrm{AOR}=2.33$; 95\%CI: 1.75-3.08).

Studies have documented that fast food consumption is an independent predictor of mean BMI. ${ }^{27,28}$ This study uncovered women consuming fast food or processed food three or more times a week had odds(3.4 times) of being overweight/ obesity(AOR=3.427, 95\% CI: 1.009-11.632) in compared to those consuming junk or fast food less than once /week (occasional). The finding was consistent with study in America ${ }^{27}$. The findings of this study revealed that energy intake was significantly associative with overweight including obesity which was consistent with studies of Kenya(58) and Belgium ${ }^{30}$ The mean energy intake was $2236.8 \pm 281.4 \mathrm{kcal} / \mathrm{day}$, which is slightly lower than the national intake of 2,536 Kcal per capita per day and energyintake at Kathmandu valley $2480 \mathrm{Kcal}$ per 
capita per day. ${ }^{31}$ These differences might be because the national average is for all type of adult population.

In this study overweight and obesity were significantly associated with physical activity and sedentary setting time $(p<0.05)$. Similar results have been reported by different studies from India, ${ }^{32}$ Bangladesh, ${ }^{35}$ Ethiopia $^{33}$ and Australia. ${ }^{34}$ Study exhibited that compared to highly physically active women, low or moderately physically active women were 2.84 times more likely (AOR=2.844; 95\%CI: $1.183-6.837)$ to be overweight including obesity, this could be compared with study findings from Ethiopia where women having moderate and low physical activity level were 3.10 times and 4.8 times more likely to be obese and overweigh respectively. ${ }^{33}$

This study finding showed that higher parity was significantly associated with overweight and obesity $(\mathrm{p}<0.05)$, similar findings were reported by other studies. ${ }^{29,32,36}$ In compared to nulliparous women, women who had given birth to two or more child (multiparious) were 17.8 times more likely ( $\mathrm{AOR}=17.803$; 95\%CI:4.046-89.067) to be overweight including obesity.

\section{CONCLUSION}

The study provides evidence that the prevalence of overweight and obesity were remarkably high in married women of reproductive age in Pokhara metropolitan. The overall prevalence of overweight and obesity among reproductive age women in Pokhara was $49.6 \%$; with $33.7 \%$ of overweight and $15.9 \%$ of obesity. The substantial proportion of women had moderate (43.1\%) physical activity level.

The study concluded older age, business as occupation, consumption of fast foods for three or more times per week, low or moderate physical activity level, energy intake above the RDA and multiparty had higher odds of being overweight/obesity. On the other hand fruits and vegetables consumption were found to be protective against overweight/obesity. Considering the changing scenario from under nutrition to over nutrition the authorities at Pokhara metropolitan should focus on framing the policies and nutrition programs with special attention among reproductive age women.

\section{CONFLICT OF INTEREST}

We declare that we have no conflict of interest.

\section{ACKNOWLEDGMENT}

We want to forward our special thanks to Institutional Review Committee of Pokhara University Research Centre for providing ethical clearance for the research. We also thank to Ms Bijaya Parajuli for her support to publish this paper.

\section{REFERENCES}

1. WHO. Fact Sheet Obesity and overweightWorld Health Organization; 2018 [29 june 2019]. Available from: https://www.who.int/news-room/fact-sheets/detail/ obesity-and-overweight.

2. WHO. The world health report 2002: Reducing Risks, Promoting Healthy Life. Geneva: World Health Organization; 2002.

3. Keil U, Kuulasmaa K. WHO MONICA Project: risk factors. International Journal of Epidemiology. 1989;18(Supplement_1):S46-S55.

4. Doak CM, Adair LS, Monteiro C, Popkin BM. Overweight and underweight coexist within households in Brazil, China and Russia. The Journal of nutrition. 2000;130(12):2965-71.

5. Aryal KK, Mehata S, Neupane S, Vaidya A, Dhimal M, Dhakal P, et al. The burden and determinants of non communicable diseases risk factors in Nepal: findings from a nationwide STEPS survey. PloS one. 2015;10(8):e0134834.

6. MOH MoHDoHS. Annual Health Report 2072/73 (2015/2016). Kathmandu: Department of Health Services, Ministry of Health, Nepal, 2016.

7. Engeland A, Bjørge T, Søgaard AJ, Tverdal A. Body mass index in adolescence in relation to total mortality: 32-year follow-up of 227,000 Norwegian boys and girls. American journal of epidemiology. 2003;157(6):517-23 .

8. Little M, Humphries S, Patel K, Dewey C. Factors associated with BMI, underweight, overweight, and obesity among adults in a population of rural south India: a cross-sectional study. BMC Obes. 2016;3:12.

9. American Obesity Association. American Obesity Association - AOA Fact Sheets 2002. Available from: http://www.fitwize4kids.com/fp/marketing/1_Research/ Statistics_Trends/AOA_FactSheets.pdf.

10. MOHP, New ERA, UNICEF, EU, USAID, CDC. Nepal National Micronutrient Status Survey, 2016. Kathmandu, Nepal: Ministry of Health and Population, Nepal, 2018.

11. Vaidya A, Shakya S, Krettek A. Obesity prevalence in Nepal: public health challenges in a low-income nation during an alarming worldwide trend. International journal of environmental research and public health. 2010;7(6):2726-44.

12. NHRC. Non Communicable Diseases Risk Factors: STEPS Survey Nepal 2013. kathmandu, Nepal: Nepal Health Research Council, 2015.

13. MOH, New ERA, ICF. Nepal Demographic and Health Survey 2016. Kathmandu, Nepal: Ministry of Health, 
Nepal, 2017.

14. NHRC, MOHP, WHO. NCD Risk Factors Surveillance In Nepal,2003. kathmandu, Nepal: Nepal Health Research Council, 2005.

15. Shrestha S, Devkota N, Shrestha R. Risk factors associated with obesity among middle aged adults residing in Bhaktapur, Nepal. Journal of Chitwan Medical College. 2018;8(3):45-50.

16. Shahi M, Rai L, Adhikari RD, Sharma M. Prevalence and factors associated with obesity among adult women of Nepal. Global Journal of Medicine and Public, GJMEDPH. 2013;2(4):1-9.

17. Padhye S. A study of Body Mass Index (BMI) of Nepalese women attending gynaecology clinic. JNMA; journal of the Nepal Medical Association. 2007;46(168):185-8.

18. 18. Bhattarai P. Risk Factors Associated With Overweight and Obesity Among Reproductive Aged Females Residing In Dharan Sub-Metropolitan City 2018.

19. Rautela YS, Reddy BV, Singh AK, Gupta A. The prevalence of obesity among adult population and its association with food outlet density in a hilly area of Uttarakhand. Journal of family medicine and primary care. 2018;7(4):809.

20. Bhardwaj S, Misra A, Misra R, Goel K, Bhatt SP, Rastogi $\mathrm{K}$, et al. High prevalence of abdominal, intra-abdominal and subcutaneous adiposity and clustering of risk factors among urban Asian Indians in North India. PloS one. 2011;6(9):e24362.

21. Agrawal P, Mishra VK. Covariates of overweight and obesity among women in North India. 2004.

22. Rawal LB, Kanda K, Mahumud RA, Joshi D, Mehata S, Shrestha N, et al. Prevalence of underweight, overweight and obesity and their associated risk factors in Nepalese adults: Data from a Nationwide Survey, 2016. PloS one. 2018;13(11):e0205912.

23. Bowie JV, Juon H-S, Cho J, Rodriguez EM. Factors associated with overweight and obesity among Mexican Americans and Central Americans: results from the 2001 California Health Interview Survey. Preventing Chronic Disease. 2007;4(1):A10-A.

24. Agbeko MP, Akwasi K-K, Andrews DA, Gifty OB. Predictors of overweight and obesity among women in Ghana. The Open Obesity Journal. 2013;5(1).

25. Rengma MS, Sen J, Mondal N. Socio-economic, demographic and lifestyle determinants of overweight and obesity among adults of Northeast India. Ethiopian journal of health sciences. 2015;25(3):199-208.
26. Gbary AR, Kpozehouen A, Houehanou YC, Djrolo F, Amoussou MP, Tchabi Y, et al. Prevalence and risk factors of overweight and obesity: findings from a crosssectional community-based survey in Benin. Global Epidemic Obesity. 2014;2(1):3.

27. Anderson B, Lyon-Callo S, Fussman C, Imes G, Rafferty AP. Peer reviewed: Fast-food consumption and obesity among michigan adults. Preventing chronic disease. 2011;8(4).

28. De Vogli R, Kouvonen A, Gimeno D. The influence of market deregulation on fast food consumption and body mass index: a cross-national time series analysis. Bulletin of the World Health Organization. 2014;92:99-107A.

29. Mbochi RW, Kuria E, Kimiywe J, Ochola S, Steyn NP. Predictors of overweight and obesity in adult women in Nairobi Province, Kenya. BMC public health. 2012;12(1):823.

30. Duvigneaud N, Wijndaele K, Matton L, Philippaerts R, Lefevre J, Thomis M, et al. Dietary factors associated with obesity indicators and level of sports participation in Flemish adults: a cross-sectional study. Nutrition Journal. 2007;6(1):26.

31. NPC NPC, Statistics CBo, Program WF, Bank W, AusAID, UNICEF. Nepal Thematic Report on Food Security and Nutrition 2013. Kathmandu, Nepal: 2013.

32. Prahlad Parameshwari HR. Obesity among Reproductive Age Women in Rural Kerala: A Hidden Threat. National Journal of Community Medcine 2017;8(9):530-4.

33. Darebo T, Mesfin A, Gebremedhin S. Prevalence and factors associated with overweight and obesity among adults in Hawassa city, southern Ethiopia: a community based cross-sectional study. BMC obesity. 2019;6(1):8.

34. Thorp AA, Healy GN, Owen N, Salmon J, Ball K, Shaw JE, et al. Deleterious associations of sitting time and television viewing time with cardio metabolic risk biomarkers: Australian Diabetes, Obesity and Lifestyle (AusDiab) study 2004-2005. Diabetes care. 2010;33(2):327-34.

35. Siddiquee T, Bhowmik B, Moreira NCDV, Mujumder A, Mahtab H, Khan AA, et al. Prevalence of obesity in a rural Asian Indian (Bangladeshi) population and its determinants. BMC public health. 2015;15(1):860.

36. Abrams B, Heggeseth B, Rehkopf D, Davis E. Parity and body mass index in US women: A prospective 25-year study. Obesity. 2013;21(8):1514-8. 